\title{
The Impact of Physical Education on Childhood Obesity in Ohio School Children: A Hierarchical Analysis
}

\author{
Nicholas V. Cascarelli Jr¹, Karen H. Larwin² \\ ${ }^{1}$ Wayne County Health Department, USA \\ ${ }^{2}$ Youngstown State University, USA
}

\begin{tabular}{l} 
Article Info \\
\hline Article history: \\
Received Jan 29, 2017 \\
Revised Feb 23, 2017 \\
Accepted Feb 28, 2017 \\
\hline Keyword: \\
Academic Achievement \\
Body Mass Index (BMI) \\
Childhood Obesity \\
Physical Education \\
Recess
\end{tabular}

\begin{abstract}
Obesity that starts in childhood or adolescence creates greater risk for adult health problems such as heart disease, arthritis, stroke, and cancer. The literature shows that childhood obesity increases most rapidly during the early elementary school years. The current investigation examines the issue of obesity using a systematic stratified random sample of Ohio schools that reported their $3^{\text {rd }}$ grader's BMI scores for the 2009-2010 school year to the Ohio Department of Health. The sample included 25 schools and 1,006 students. Those schools selected were contacted via phone to ask how many minutes per week schools allocated for physical education in grades $\mathrm{K}-3$, and how many minutes per day was allotted for recess in grades K-3. The analysis also examined potential moderators including the percentage of students receiving free or reduced lunch and the school building academic performance designations as indicated on the Ohio Department of Education webpage. The results suggest that the model run at the student level accounts for approximately $1 \%$ of the variation in BMI; the model run at the school level was not a significant predictor of the variance. While the model included for Ohio students did not indicate a strong predictor for childhood obesity, schools can play a significant role in addressing the childhood obesity issue.
\end{abstract}

Copyright (C) 2017 Institute of Advanced Engineering and Science. All rights reserved.

\section{Corresponding Author:}

Karen H. Larwin,

Youngstown State University, One University Circle, Youngstown, Ohio, USA.

Email: khlarwin@ysu.edu

\section{INTRODUCTION}

Childhood obesity has become a significant public health problem over the last 35 years. According to the 2007-2008 National Health and Nutrition Examination Survey (NHANES), the prevalence of obesity among children two to 19 years old is approximately 18\% [1]. This represents approximately a $300 \%$ increase from the obesity prevalence from 1980 [2],[3]. While the etiology of obesity is multifaceted, it is likely rooted in the social and behavioral determinants of health. For example, a recent meta-analysis aimed to determine the sources of a sedentary lifestyle in school-aged children ages five to 17 and found that watching two hours or more of television per day was associated with obesity [4]. Several studies included in the meta analysis were interventions to combat childhood obesity and were successful to varying degrees. Childhood obesity has long term consequences for children's health. Children who are obese tend to be more at risk for hypertension, hyperlipidemia (high cholesterol), pre-diabetes/diabetes, bone and joint problems, sleep apnea, and psychological issues associated with being overweight [5]-[7]. In a population-based study of 5-17 year olds, over two thirds of obese children had one or more risk factors for cardiovascular disease $[5]$.

The primary consequence to this problem is that obese children and adolescents are more likely to become obese adults [8]. The Office of the Surgeon General [9] released a report stating that this obesity, 
which starts in childhood or adolescence, puts obese adults at greater risk for adult health problems; most notably, heart disease, stroke, arthritis, and cancer.

Over the last 35 years, at the same time childhood obesity prevalence is trending upward, U.S. children's achievement in crucial subjects such as reading and math have been falling behind other Office of Economic Cooperation and Development (OECD) countries [10]. In response, schools across the United States began narrowing the focus of their curricula. These policy changes may have had some unintended consequences as NCLB resulted in schools trying to increase health and physical education activities. Schools have some capacity to make a difference in the fight against childhood obesity. According to Kahan and McKenzie [11], if schools would implement nationally recommended physical education standards from grades 1-10, students could expend an additional 35,000 to 90,000 kilocalories than compared to students who just receive instruction without physical education. It has yet to be demonstrated that reducing the amount of time in the curriculum dedicated for physical education in favor of other subjects, such as math and reading, improves academic performance [12]. On the other hand, other studies have found positive associations between physical activity, cognition, and academic performance [13],[14]. Thus, schools can be an excellent venue for, addressing childhood obesity [15]. While Brescoll et al. acknowledged there is not one magic bullet for this issue, interventions that change policy in the elementary school environment would have the most impact on reducing childhood obesity. Children spend a significant proportion of their lives in school. The body of literature on childhood obesity interventions implemented in schools is vast. Brownson, Chiquri, Burgeson, Fisher, and Ness [16] found that a good, school-based, physical education program should dedicate more time to physical education than has been traditionally provided. Making policy changes can be limited by constraints in which schools operate i.e., the need to demonstrate adequate yearly progress (AYP).

Cawley, Frisvold, and Meyerhoefer [17] found that at the fifth-grade level, an increased amount of PE time increases the likelihood a child will be within a healthy weight, according to the BMI scale. Using data collected during 2004, they found that, if schools, on average, would increase their amount of weekly physical education time by 50 minutes, it could significantly reduce BMI percentages. One other point this research makes is that socioeconomic status (SES), and the level of intensity of physical activity, can be potential moderators to this relationship between physical education and obesity. While physical education is a substantial factor impacting childhood obesity, examining this as a causal relationship, however, is not very common. Mediating variables such as SES, school performance, location of school, or health education curriculum are acknowledged in the literature. This research attempts to take into account all of these variables and examine the relationships. The one intended outcome of this research is to aid in changing school policies to increase, not only the time, but also the quality and focus of physical education instruction. This is extremely crucial now that there is an increased emphasis on subjects such as math and reading, which has resulted in reduced time allotted to other subjects, including physical education.

\subsection{When Childhood Obesity Occurs}

Childhood obesity increases most rapidly during elementary school years. In a study of data from the Early Childhood Longitudinal Study using the kindergarten data during the 1998-1999 school year, $14.9 \%$ and $12.9 \%$ of children entering kindergarten were overweight or obese, and $20.8 \%$ reached obesity by the eighth grade [18]. Cunningham et al. also noted that they found no significant increases in prevalence of obesity between the ages of 11-14. Consequently, this demonstrates that most of the weight gain actually occurs in the early elementary years, and provides rationale for the importance of recognizing and planning interventions to prevent or address obesity for children during early elementary school years. Another problem associated with early childhood obesity is early onset of puberty, especially in girls [19]. This adds to the importance of understanding childhood obesity into the early elementary years. One major moderator of childhood obesity is the socioeconomic status of the child. Gundersen, Mahatmya, Garasky, and Lohman [20], conducted a meta-analysis that indicated that psychosocial stressors, which occur to a greater degree in low SES households, are causal agents of poor health indicators; most notably, obesity.

Disadvantaged children often attend school districts that have less than optimal resources and facilities conducive to the best physical education. Fernandes and Sturm [21] found that schools that did not have gymnasiums provided close to 10 minutes less, per week, of physical education time than their counterparts that had gymnasiums. In a study of Massachusetts' families with children, 109,634 children from grades 1, 4, 7, and 10 had BMI measurements taken in schools during the 2009 school year. There was an inverse relationship between income and percentage of children with BMIs above the $85^{\text {th }}$ percentile, which is the BMI level for classification as overweight [22]. 


\subsection{Community Type and Childhood Obesity}

There tends to be some overlap with SES and the community environment, as many people of lower SES also live in urban or rural areas. One of the problems with urban areas is that the "built environments" in which they are contained do not often have characteristics conducive to physical activity. Built environments refer to infrastructures that are not conducive to exercise, such as sidewalks, parks, and recreation centers. These built environments in lower SES communities are often unsafe, contain poor housing, and have little or no access to sidewalks, parks, or recreation centers [23]. Children in these environments are anywhere from $20 \%$ to $60 \%$ more likely to be overweight, or obese, than their counterparts in suburban environments. The effects found by Singh et al. [23] were greatest for younger children and female children.Rural areas, at first glance, may appear to be more conducive to physical activity than urban areas. However, Moore, Brinkley, Crawford, Evenson, and Brownson [24] found that there were no differences in Body Mass Index (BMI) between rural and urban youth. Moore et al. studied rural middle school youth and middle school youth at an adjacent urban school district. One of the considerations for this finding of no differences in BMI was that the urban students averaged more time $(19.2 \mathrm{~min} /$ day $)$ in moderate to vigorous physical activity compared to the rural students' (15.9 min/day). Another important aspect related to physical activity also involves the level of vigor of the physical activity. One study of rural, Oregon elementary students found a significant inverse association: students who were involved in moderate to vigorous physical activity (MVPA) were more likely to have lower BMIs [25]. These findings were independent of sex and grade. The authors' conclusion was that rural schools are falling short of the recommended 60 minutes of MVPA/day, as $38.4 \%$ of students were overweight, and $19.4 \%$ were obese. Schools need to place more emphasis on opportunities for MVPA. Other studies of rural environments also show high rates of obesity. Greening, Harrell, Low, and Fielder [26] conducted a study of 450 rural Mississippi children, ages 6-10, to measure the effectiveness of a school-based obesity intervention program. Over 50\% of these children were overweight/ obese. This research did not yield statistically significant differences in BMI when comparing the experimental group with a control group pre- and post-intervention. However, there were statistically significant differences between groups when it came to increasing physical activity and improved dietary habits. The duration of this study was nine months. Perhaps a one-time intervention is less preferable to institutionalizing a greater emphasis on physical activity.

\subsection{The Importance of Physical Education}

Lee, Burgeson, Fulton, and Spain [27] surveyed 988 schools and 1,194 physical education teachers across the United States. They found that less than $50 \%$ of schools in the United States were required to offer physical education in kindergarten. This percentage reaches its peak in the sixth grade, at $68.1 \%$. After that, it falls to $20.4 \%$, by the time a child reaches the twelfth grade. With this inconsistency in reinforcement of healthy lifestyles across the grades, and, the fact that, at its best, only $68 \%$ of schools are required to offer physical education, this may contribute to a sedentary lifestyle. Because children spend a great deal of time in school, it is plausible to argue that the limited amount of physical education children receive in school is part of the problem with child obesity rates in schools. In a study of kindergarten and first grade students, Datar and Sturm [28] argued that expanding physical education in elementary schools, to at least five hours a week, can significantly combat obesity among overweight, or at-risk-for overweight children. This effect was found to be significant for girls. There maybe many other factors that could account for obesity in children. Some of those will be explored in the present study.

One way to address the reduction in time allotted for physical education and increasing the health benefit is to increase the intensity of the exercise for students [29]. Using schools as the unit of analysis, McKenzie et al. [29] found that standardizing training for physical educators, to incorporate more moderate to vigorous exercise activities into their curricula, can improve the quality of instruction for middle school students. Providing more staff development time for physical education teachers, for this and other purposes, is both a feasible and impactful policy change to address childhood obesity [15].

\subsection{Physical Fitness and Academic Achievement}

Children who have a sedentary lifestyle will be at higher risk for becoming overweight or obese. Using a Randomized Control Trial (RCT) design, Davis et al. [30] evaluated differences of 171, 7-11-yearold, sedentary, overweight children, and exposed the test group to 13 weeks of an exercise program for 20-40 minutes of per day that the control group did not receive. Davis et al. used standardized, psychological evaluations that assessed cognition and academic achievement. They also used functional, magnetic resonance imaging (MRI) to measure brain activity during executive functioning tasks. They concluded that executive function and brain activation changes were observed in the test group. Increasing the amount and vigor of PE time provides both positive health outcomes and positive educational outcomes, especially for elementary, overweight children [13],[14],[30]. Obesity and physical activity were found to influence the 
relationship between childhood motor function and academic achievement in adolescents [31]. In a 1986 birth cohort of 8,061 children, born in northern Finland, physical activity was associated with a higher-grade point average, and obesity was associated with lower grade point average. As obesity and physical activity were considered influential factors in Kantomaa et al. [31], the proposed research will test the relationship between physical activity and obesity rates. Community type, academic achievement, SES, and gender will be treated as mediators.

\subsection{Current Investigation}

Childhood obesity has been widely studied. The current investigation will address a gap in the literature by assessing, on a large scale, the relationship variying amounts of time allotted for physical education in the curriculum and obesity rates among elementary school children in Ohio. The intention is not to indict schools as the cause of childhood obesity. The intention is to demonstrate whether schools can be a larger part of the solution. As such, the current investigations seek to examine the extent to which a school's physical education curriculum impacts a child's propensity for being overweight or obese, defined by Body Mass Index percentile (BMI percentile). The proposed research will further examine modifying factors (rate of students receiving free or reduced school lunch, within which type of community the school district resides, the time in the curriculum dedicated to health education, and the school district performance) that may mediate the relationship between the curriculum time dedicated to the physical education in $\mathrm{K}-3^{\text {rd }}$ grade and a child's BMI in the third grade. The scope of the study is limited because the BMI data are collected only in the third grade.

\section{RESEARCH METHOD}

This study is an ex post facto quantitative design to determine the impact of the time devoted to weekly physical education and recess in grades K-3 on the BMI of the students in the third grade. Because there are many factors that contribute to childhood obesity, other factors such as community type, percentage of children eligible for free or reduced lunch and school performance designation will be examined as mediators.

\subsection{Participant Sample}

The sample was a systematic stratified random sample of Ohio public elementary schools that reported their $3^{\text {rd }}$ grade BMI scores for 2009-2010 school year to the Ohio Department of Health. The data were stratified to ensure representation of rural, Appalachian, suburban, and metropolitan school districts.

The elementary schools that were included from the sample population were schools that conducted BMI measurements on their third-grade students and reported them to the Ohio Department of Health. Schools had the ability to opt out of reporting to the Ohio Department of Health and it did not include students attending private schools. Although the students and schools were randomly selected from a larger list of schools, they were not randomly selected from the entire list of elementary schools and students in Ohio.

\subsection{Procedures}

A stratificed random sample of school districts reporting BMI was used to select 60 school districts. Each school district was contacted using a prepared script to describe the purpose of the study, to assure the school district will be identified in the study, and to ask the administrator or PE director two questions related to curriculum for that school year. The contacted schools provided information on the independent variables: the amount of time, in minutes per week, devoted to physical education grades for K-3, and the amount of time dedicated to daily recess in grades K-3. Twenty-five $(41.67 \%)$ of the 60 selected in the sample responded to the questions about physical education, curriculum, and recess. These schools accounted for a total of 1,006 students. The data regarding the schools' academic performance were acquired from the Ohio Department of Education. The balance of the data, including the BMI measurements of the children, type of community (metropolitan, Appalachian, suburban, or rural), free or reduced lunch, and demographic variables were included in data provided by the Ohio Department of Health.

\section{RESULTS AND ANALYSIS}

The sample of data from 25 schools included 512 (50.9\%) male students and $494(49.1 \%)$ female students. The BMI data provided included a raw BMI and a BMI percentile adjusted for age and sex. BMI percentile adjusted for age and sex was chosen for data analysis because (a) there was no consistency when the BMIs were conducted in one school to the next, (b) because children are still growing, and (c) the 
provided age-adjusted BMI isa more accurate measure to age (in months) and gender when calculating the BMI for children. Table 1 is a listing of where the children included in the analysis, ranked in terms of their BMI percentile - underweight, healthy weight, overweight, or obese.

Table 1. BMI Percentile Adjusted for Age and Sex

\begin{tabular}{lcc}
\hline \multicolumn{1}{c}{ BMI Percentile } & Frequency & Percent \\
\hline Underweight $(<5 \%)$ & 17 & 1.7 \\
Healthy Weight $(5-84 \%)$ & 653 & 64.9 \\
Overweight $(85-94 \%)$ & 158 & 15.7 \\
Obese $(>85 \%)$ & 178 & 17.7 \\
\hline
\end{tabular}

Table 1 appears to show that most of the children were at a healthy weight. However, close examination reveals that over $1 / 3(33.4 \%)$ of the children in the sample are either overweight or obese. Of these students, $n=376$ (37.4\%) were reported as living in poverty as defined by the Ohio Department of Education by receiving free or reduced lunch. Table 2 displays the breakdown of the sample of schools by community type.

Table 2. Distribution of Students by Community Type

\begin{tabular}{lcc}
\hline \multicolumn{1}{c}{ Community type } & Frequency & Percent \\
\hline Metro & 169 & 16.8 \\
Suburban & 437 & 43.5 \\
Appalachian & 198 & 19.7 \\
Rural & 202 & 20 \\
\hline
\end{tabular}

Additionally, the school performance designations for the 2009-2010 school year are displayed by student. These breakdowns are presented in Table 3.

Table 3. School Performance Designation

\begin{tabular}{lcc}
\hline School Designation & Student_Frequency & Percent \\
\hline Academic emergency & 45 & 4.5 \\
Continuous improvement & 92 & 9.2 \\
Effective & 282 & 28 \\
Excellent & 495 & 49.3 \\
Excellent with distinction & 90 & 9 \\
\hline
\end{tabular}

It is important to note that almost half of the students in the sample attended a school with an excellent designation, while this accounted for a little less than $33 \%$ of schools that responded. Table 4 provides the breakout of children reported living at the poverty level.

Table 4. Children in Poverty

\begin{tabular}{lcc}
\hline Poverty Designation & Frequency & Percent \\
\hline Living in Poverty & 376 & 37.4 \\
Not living in poverty & 630 & 62.6 \\
\hline
\end{tabular}

As indicated in Table 4, 37.4\% of the students included in the analysis live in poverty as defined by the Ohio Department of Education by receiving free or reduced lunch. As indicated above, the weekly number of minutes dedicated to physical education and recess time were provided by each school included in the analyses. Table 5 presents the minutes allocated for physical education for kindergarten through $3^{\text {rd }}$ grade students. It is important to note that the total students included in each of the following tables do not equal one another because not all schools that responded have grades K-3. One common theme throughout all four grade levels was that 40 minutes of physical education per week was the most frequent amount of time allotted. 
Table 5. Percentage of Students by Minutes Per Week of Physical Education

\begin{tabular}{ccccc}
\hline Minutes & $\mathrm{K}$ & 1st & 2nd & $3^{\text {rd }}$ \\
\hline 10 & 6.1 & 6.1 & 5.7 & 5.3 \\
30 & 17.6 & 17.6 & 22.1 & 15.2 \\
40 & 34.1 & 27.4 & 25.6 & 23.8 \\
45 & 16.2 & 16.2 & 15.1 & 14.0 \\
50 & 6.7 & 13.3 & 12.4 & 11.5 \\
55 & 5.4 & 5.4 & 5.0 & 4.7 \\
60 & 7.9 & 7.9 & 7.4 & 6.9 \\
70 & - & - & 6.5 & 6.1 \\
80 & 2.2 & 2.2 & 2.0 & 9.2 \\
90 & 2.5 & 2.5 & 2.4 & 2.2 \\
100 & 1.4 & 1.4 & 1.3 & 1.2 \\
\hline
\end{tabular}

Table 6 presents the minutes per day of recess for students in kindergarten through third grade. One common theme throughout all four grade levels was that 30 minutes of recess was the mode of the time allotted. The distribution of recess minutes is relatively consistent across the grades for each time category.

Table 6. Percentage of Students Per Week by Minutes Per Day of Recess

\begin{tabular}{ccccc}
\hline Minutes & $\mathrm{K}$ & $1 \mathrm{st}$ & $2 \mathrm{nd}$ & $3^{\text {rd }}$ \\
\hline 15 & 2.4 & 2.4 & 2.3 & 2.1 \\
20 & 16.9 & 19.5 & 18.2 & 16.9 \\
25 & 10.0 & 10.0 & 9.3 & 8.6 \\
30 & 44.2 & 54 & 50.4 & 59.1 \\
45 & 22.3 & 9.9 & 9.2 & 3.5 \\
50 & 4.2 & 4.2 & 10.5 & 9.7 \\
\hline
\end{tabular}

\subsection{Preliminary Analyses}

Preliminary analysis reveals that the average age-adjusted BMI is $\mathrm{M}=64.52$ ( $\mathrm{sd}=7.21)$. Results indicated that the skewness and kurtosis for the Adjusted BMI are within acceptable levels as they were both less than $|2.0|$ and $|5.0|$ respectively [32]. A zero-order correlation analysis between BMI and mediating factors (Community Type, Poverty, and School Performance) and independent variables (Physical Education and Recess for grades K-3) was conducted. The results of this correlation indicate that the only variables significantly correlated with Adjusted BMI are third grade recess $(r=.064, p<.05)$, community type $(r=$ $.057, p<.05)$, and poverty status $(r=.062, p<.05)$. Although significant, all three of these variables presented weak correlations with BMI.

\subsection{Regression Analysis: Student Level Analysis}

Regression analyses were considered the most appropriate strategy for answering the proposed research question. A sequential multiplelinear regression analysis was conducted to evaluate the prediction of BMI, adjusted for age and sex, from the correlations that showed a significant relationship to BMI: Recess in grade 3, and, Community Type, and Poverty. The dependent variable, BMI, adjusted for age and sex, was a continuous variable; the independent variables were quantitative, with third grade Recess and Poverty being a discrete variable, and Community Type being a nominal variable. The regression was conducted in two models. The initial model included the dependent variable and all three predictor variables. The second model was conductedwithout the Community Type variable because the coefficient was no longer significant in the first regression model. However, it did not add to the model by taking it out, and the first model accounted for more of the variance in BMI. The resultant regression model is as follows: $\mathrm{BMI}=53.88+$ 3.99 (poverty) +1.34 (Community Type) +.219 (Third grade recess). The characteristics of the two models are indicated on Table 7.

As indicated in Table 1, Model One, with the all three independent variables, resulted in an $R^{2}=$ $0.011, F(3,1001)=3.726, p=0.011$. Model Two, with the subtraction of the Community Type variable revealed a less powerful $R^{2}=0.009, F(2,1003)=4.481, p=.012$. This pattern of results suggested both models account for approximately $1 \%$ of the variation in BMI, with Model Two accounting for two-tenths of $1 \%$ less than the first model. 
Table 7. Model One and Model Two Results at Student Level

\begin{tabular}{|c|c|c|c|}
\hline & B & SE B & $\beta$ \\
\hline Model One & & & \\
\hline$\overline{\text { Constant }}$ & 53.88 & 3.88 & \\
\hline Poverty & 3.99 & 1.86 & .068 \\
\hline Community Type & 1.34 & .908 & .047 \\
\hline $\begin{array}{l}\text { Third grade recess } \\
\text { Model Two }\end{array}$ & .219 & .108 & .065 \\
\hline Constant & 55.96 & 3.468 & \\
\hline Poverty & 4.09 & 1.85 & .070 \\
\hline Third grade recess & .241 & .11 & .071 \\
\hline
\end{tabular}

\section{DISCUSSION AND CONCLUSION}

The first objective of this investigation was to examine if the amount of physical education or recess a school provides has an impact on a child's BMI. The hypotheses specific to this objective was that there would be an inverse relationship between the amount of physical education and recess time offered in school and the child's resulting BMI. In examining these relationships in this particular study, the only statistically significantly correlated variable among the physical activity variables was the amount of recess offered in the third grade. Several studies have indicated that increasing time allotted for physical education can significantly impact childhood obesity [13],[15],[16].

The second objective was to examine if other variables modified the effects of the association between BMI and the amount of physical education and recess. Specifically, community type, district academic performance, and poverty were examined. While not strong, the type of community in which the school district is located yielded significant results in the current study, which concurs with the literature on the environment being a part of the BMI percentile equation [23],[24]. Secondly, there was no significant correlation between the school district academic performance designation and the independent variable of adjusted BMI. This is counter to much of the literature that suggests that there is a relationship between academic achievement and BMI, especially at the elementary school [13],[15],[16]. Lastly, the finding that socioeconomic status is related to childhood obesity is pervasive throughout the literature. Several metaanalyses and single case studies have supported the concept that there is an inverse relationship between income and percentage of children with high BMI percentiles [20],[21],[22]. The current research demonstrated that socioeconomic status and the students' BMI adjusted for sex and age are significantly related. Even though poverty was a weak but significant correlation to BMI, was the most powerful predictor, $\beta=3.99$, which was more than double the next closest predictor. However, socioeconomic status as indicated by free or reduced lunch, along with community type and third grade recess time only accounted for $1 \%$ of the variance in BMI adjusted for age and sex.

\subsection{Conclusions}

The purpose of the current research was to determine if physical activity-- specifically defined as the amount of time allotted for physical education in minutes per week and amount of the time allotted for recess in minutes per day -- impacted a student's BMI. In the current research, the prediction related to the relationship of physical activity and BMI that third grade recess was related to BMI in the sample. Third grade recess was statistically significant as part of the regression model, but a weak predictor of BMI. The amount of time devoted to physical education and recess across schools was homogenous across the participating schools. This lack of diversity in time allotted for physical education and recess coupled with the large sample size could reasonably explain the lack of power in the resulting analysis model. The current research also sought to determine if various factors found throughout the literature acted as mediators in this relationship. The implications of this study are that school performance is not necessarily related to BMI. Additionally, the findings suggest that community type and socio-economic identifiers (receiveing free or reduced lunches) are significant predictors of BMI. More research is needed that can further examine how these types of variables might moderate the relationship, and whether school lunches, the presence and use of vending machines, and/or bus transportation or walking to school play a role in students' physical fitness.

\section{REFERENCES}

[1] C. L. Ogden, et al., "Prevalence of obesity and trends in body mass index among US children and adolescents, 1999-2010," Journal of the American Medical Association, vol/issue: 307(5), pp. 483-490, 2012.

[2] Flegal K. M., et al., "Overweight and obesity in the United States: Prevalence and trends, 1960-1994," International Journal of Obesity Related Metabolic Disorders, vol/issue: 22(1), pp. 39-47, 1998. 
[3] Flegal K. M., et al., "Prevalence and trends in obesity among US adults, 1999-2000," Journal of the American Medical Association, vol/issue: 288(14), pp. 1723- 1727, 2002.

[4] M. S. Tremblay, et al., "Systematic review of sedentary behavior and health indicators in school-aged children," International Journal of Behavioral Nutrition and Physical Activity, vol/issue: 8(98), pp. 1-22, 2011.

[5] D. S. Freedman, et al., "Cardiovascular risk factors and excess adiposity among overweight children and adolescents: The Bogalusa heart study," Journal of Pediatrics, vol/issue: 150(1), pp. 12-17, 2007.

[6] C. Li, et al., "Prevalence of pre-diabetes and its association with clustering of cardiometabolic risk factors and hyperinsulinemia among US adolescents: NHANES 2005-2006," Diabetes Care, vol. 32, pp. 342-347, 2009.

[7] W. H. Dietz, "Overweight in childhood and adolescence," New England Journal of Medicine, vol. 350, pp. 855857, 2004.

[8] S. S. Guo and W. C. Chumlea, "Tracking of body mass index in children in relation to overweight in adulthood," American Journal of Clinical Nutrition, vol. 70, pp. S145-S148, 1999.

[9] Office of the Surgeon General, "The Surgeon General's vision for a healthy and fit nation," Rockville, MD, U.S. Department of Health and Human Services, 2010.

[10] L. O. Gostin and J. Pomeranz, "Improving laws and legal authorities for obesity prevention and control," Journal of Law, Medicine and Ethics, vol. 37, pp. 62-75, 2009.

[11] D. Kahan and T. L. McKenzie, "The potential and reality of physical education in controlling overweight and obesity," American Journal of Public Health, vol/issue: 105(4), pp. 653-659, 2015.

[12] F. Trudeau and R. J. Shepherd, "Physical education, school physical activity, school sports and academic performance," International Journal of Behavioral Nutrition and Physical Activity, vol/issue: 5(1), pp. 10-21, 2008.

[13] D. M. Castelli, et al., "Physical fitness and academic achievement in third and fifth grade students," Journal of Sport \& Exercise Psychology, vol. 29, pp. 239-252, 2007.

[14] J. E. Donnelly and K. Lambourne, "Classroom-based physical activity, cognition, and academic achievement," Preventative Medicine, vol. 52, pp. 36-42, 2011.

[15] V. L. Brescoll, et al., "Assessing the feasibility and impact of federal childhood obesity policies," The Annals of the American Academy of Political and Social Science, vol/issue: 615(1), pp. 178-194, 2008.

[16] R. C. Brownson, et al., "Translating epidemiology into policy to prevent childhood obesity: The case for promoting physical activity in school settings," The Annals of Epidemiology, vol/issue: 20(6), pp. 436-444, 2010.

[17] J. Cawley, et al., "The impact of physical education on obesity among elementary school children," Discussion Paper series, ForschungsinstitutzurZukunft der Arbeit, No. 6807, 2012.

[18] S. A. Cunningham, et al., "Incidence of childhood obesity in the United States," New England Journal of Medicine, vol. 370, pp. 403-11, 2014.

[19] P. B. Kaplowitz, "Link between Body Fat and the Timing of Puberty," Pediatrics, vol. 121, pp. S208, 2008.

[20] C. Gundersen, et al., "Linking psychosocial stressors and childhood obesity," Obesity Reviews, vol. 12, pp. e54e63, 2011

[21] M. Fernandes and R. Sturm, "Facility provision in elementary schools: Correlates with physical education, recess, and obesity," Preventative Medicine, vol. 50, pp. S30, 2010.

[22] T. F. Eagle, et al., "Understanding childhood obesity in America: Linkages between household income, community resources, and children's behaviors," American Heart Journal, vol/issue: 163(5), pp. 836-843, 2012.

[23] G. K. Singh, et al., "Neighborhood socioeconomic conditions, built environments, and childhood obesity," Health Affairs, vol/issue: 29(3), pp. 503-512, 2010.

[24] J. B. Moore, et al., "Association of the built environment and adiposity in rural and urban youth," Preventative Medicine, vol/issue: 56(2), pp. 145-148, 2012.

[25] K. B. Gunter, et al., "Physical activity levels and obesity status of Oregon rural elementary school children," Preventative Medicine Reports, vol. 2, pp. 478-482, 2015.

[26] L. Greening, et al., "Efficacy of a school-based childhood obesity intervention program in rural southern community: TEAM Mississippi project," Obesity, vol/issue: 19(19), pp. 1213-1219, 2011.

[27] S. M. Lee, et al., "Physical education and physical activity: Results from the school health policies and programs study 2006," Journal of School Health, vol. 77, pp. 435-463, 2007.

[28] A. Datar and R. Sturm, "Physical education in elementary school and body mass index: Evidence from the early childhood longitudinal study," American Journal of Public Health, vol/issue: 94(9), pp. 1501-1506, 2004.

[29] T. L. McKenzie, et al., "Evaluation of a two-year middle-school physical education intervention: M-SPAN," Medicine \& Science in Sports \& Exercise, vol/issue: 36(8), pp. 1382-1388, 2004.

[30] C. L. Davis, et al., "Exercise improves executive function and achievement and alters brain activation in overweight children: A randomized control trial," Health Psychology, vol/issue: 30(1), pp. 91-98, 2011.

[31] M. T. Kantomaa, et al., "Physical activity and obesity mediate the association between childhood motor function and adolescents' academic achievement," Proceedings of the National Academy of Sciences, vol/issue: 110(5), pp. 1917-1922, 2012.

[32] A. Field, "Discovering statistics using SPSS (3rd ed.)," Los Angeles, CA, Sage, 2009. 


\section{BIOGRAPHIES OF AUTHORS}

Dr. Nicholas V. Cascarelli has been a public health professional for over 17 years. He currently serves
as the Health Commissioner of the Wayne County Health Department in Ohio. He also serves as an
adjunct faculty member for the Department of Health Professions at Youngstown State University
where he teaches undergraduate research and graduate level community health courses. His research
interests and expertise includes population based health interventions related to childhood obesity,
tobacco use, childhood lead poisoning and vaccination utilization. He currently resides in Wooster,
Ohio with his wife of 23 years, Christina and their three children Nadia 8, Nico 5 and Mila 3.

